\title{
Humin Assists Reductive Acetogenesis in Absence of Other External Electron Donor
}

\author{
Mahasweta Laskar ${ }^{1,2}$, Takuya Kasai ${ }^{1,2}$, Takanori Awata ${ }^{3}$ and Arata Katayama $1,2, *$ (D) \\ 1 Graduate School of Engineering, Nagoya University, Nagoya 464-8603, Japan; \\ laskar.mahasweta@k.mbox.nagoya-u.ac.jp (M.L.); kasai.takuya@imass.nagoya-u.ac.jp (T.K.) \\ 2 Institute of Materials and Systems for Sustainability, Nagoya University, Nagoya 464-8603, Japan \\ 3 National Institute for Land and Infrastructure Management, Tsukuba 305-0804, Japan; \\ awata-t92yu@mlit.go.jp \\ * Correspondence: katayama.arata@nagoya-u.jp; Tel.: +81-(0)52-789-5856
}

Received: 7 May 2020; Accepted: 7 June 2020; Published: 12 June 2020

\begin{abstract}
The utilization of extracellular electron transfer by microorganism is highly engaging for remediation of toxic pollutants under "energy-starved" conditions. Humin, an organo-mineral complex of soil, has been instrumental as an external electron mediator for suitable electron donors in the remediative works of reductive dehalogenation, denitrification, and so forth. Here, we report, for the first time, that humin assists microbial acetogenesis as the extracellular electron donor using the electron acceptor $\mathrm{CO}_{2}$. Humin was obtained from Kamajima paddy soil, Japan. The anaerobic acetogenic consortium in mineral medium containing $\mathrm{CO}_{2} / \mathrm{HCO}_{3}^{-}$as the inorganic carbon source used suspended humin as the energy source under mesophilic dark conditions. Retardation of acetogenesis under the $\mathrm{CO}_{2}$-deficient conditions demonstrated that humin did not function as the organic carbon source but as electron donor in the $\mathrm{CO}_{2}$-reducing acetogenesis. The consortium with humin also achieved anaerobic dechlorination with limited methanogenic activity. Total electron-donating capacity of humin was estimated at about $87 \mu \mathrm{eeq} / \mathrm{g}$-humin. The metagenomic sequencing of $16 \mathrm{~S}$ rRNA genes showed the predominance of Firmicutes $(71.8 \pm 2.5 \%)$ in the consortium, and Lachnospiraceae and Ruminococcaceae were considered as the $\mathrm{CO}_{2}$-reducing acetogens in the consortium. Thus, microbial fixation of $\mathrm{CO}_{2}$ using humin introduces new insight to the holistic approach for sustainable treatment of contaminants in environment.
\end{abstract}

Keywords: humin; reductive acetogenesis; $\mathrm{CO}_{2}$ reduction; autotrophic; dechlorination; methanogenesis

\section{Introduction}

The anaerobic nonphototrophic $\mathrm{CO}_{2}$ fixers are abundant in nature [1,2], and though energetics of $\mathrm{CO}_{2}$ reduction to acetate is less favorable than methanogenesis, the ability to use diverse electron donors sets the acetogens apart from the other microbial populations [3,4]. From the variability in chemolithotrophic acetogenesis [5]; to electron harvest using electricity [6]; to higher biochemical efficiency during $\mathrm{CO}_{2}$ fixation [7], reductive acetogenesis attracted much attention, particularly for the autotrophic Wood-Ljungdahl pathway (WLP) in acetate production $\left(2 \mathrm{CO}_{2}+4 \mathrm{H}_{2} \rightarrow \mathrm{CH}_{3} \mathrm{COOH}+2 \mathrm{H}_{2} \mathrm{O}\right)$ [8], although the reaction requires highly reduced conditions $-290 \mathrm{mV}$ [1] as standard redox potential at $\mathrm{pH} 7\left(E^{o^{\prime}}\right)$. In dark subsurface environments where organic substrates and energy are limited, acetate produced by the autotrophic WLP can be utilized by anaerobic microbial consortium as a carbon and energy source for reductive dehalogenation (organohalide respiration) in bioremediation of toxic substances [9-11].

Humic substances (HSs) are the key component of the carbon cycle on the earth, attained by virtue of biogeochemical transformation and long residence time of soil organic matter with mineral 
compounds [12-14]. Humin is understood as the insoluble fraction of HSs at any $\mathrm{pH}$ in the form of an organo-mineral complex, and constitutes the dominant fraction of HSs in environment $[15,16]$. Although only soluble form of HSs was considered to function as extracellular electron mediator (EEM) before [17,18], solid-phase HSs including humin have also been found to function as EEM [19-21].

The isoelectric point of humin was estimated to range from $+8 \mathrm{mV}$ to $-300 \mathrm{mV}$ (vs. standard hydrogen electrode, SHE) when measured using sodium sulfate as the electrolyte with DMSO (dimethyl sulfoxide) as the solvent; while showed redox peak at two positive potentials of $+272 \mathrm{mV}$ and $+5 \mathrm{mV}$ (vs. SHE) when anaerobic mineral medium was used as the solvent $[19,22]$. The versatility of humin thus, as EEM functioning for reducing reactions ranging from organohalide respiration [19,23]; denitrification [24]; iron(III) reduction; to dissimilatory nitrate reduction to ammonia [25], was limited to energetically favored conditions with the use of organic substrate (formate [26], lactate [27], etc.), chemical reducing agent (sodium borohydride [28]), and so on for external electron donation.

In retrospect to the interest in use of many conductive solid surfaces like modified graphene oxide [29], carbon nanotubes [30], and so forth, as the extracellular interface for electron shuttle in microbial $\mathrm{CO}_{2}$ reduction to acetate, little attention was given to humin as the EEM [31] despite its versatility in redox mediation and, in particular, under energy-limited conditions, a key feature distinguishing the electroautotrophic microorganisms from others [32,33].

Thus, the present study examined the effect of humin as the solid material for electron shuttle under energy-limited conditions for nonphototrophic anaerobic $\mathrm{CO}_{2}$ reduction to produce acetate by a mixed consortium when no external source of energy, as either organic or inorganic, was provided with sole exception to humin.

\section{Materials and Methods}

\subsection{Humin Extraction from Kamajima Soil}

Humin was extracted from Kamajima paddy soil, Aichi prefecture, Japan, as previously reported [34]. Briefly, the sieved soil (2 $\mathrm{mm} \varnothing$ pore sieving) suspended in pure water was segregated by repeated decantation of time seven seconds each. The decanted finer particles of soil were then washed alternately by the chemicals- $2 \%$ hydrofluoric acid (HF) and $0.1 \mathrm{~N}$ sodium hydroxide $(\mathrm{NaOH})$ - for the elimination of clay particles, metallic ions, or humic and fulvic acids. The washing was carried out using a mechanical shaker (Taitec TS-20, Tokyo, Japan) for $24 \mathrm{~h}$, followed by the centrifugation at $8000 \times g$ (Kubota 7780, Tokyo, Japan). The insoluble fraction obtained from soil after the washing with chemicals was neutralized to $\mathrm{pH} 7$ using $0.1 \mathrm{~N}$ hydrochloric acid $(\mathrm{HCl})$, further washed with pure water to eliminate trace chloride, and finally freeze-dried. The freeze-dried sample was finely powdered using mortar and pestle for the use as humin.

\subsection{Development of Bacterial Consortium PCPA0 and Experimental Conditions}

The source inoculum was obtained from a lactate-utilizing pentachorophenol-dechlorinating consortium (LC) maintained with Kamajima soil in the laboratory. The consortium PCPA10 was developed from LC in an anaerobic mineral medium (Med-A) amended with $10 \mathrm{mM}$ sodium acetate (Na-acetate) as organic electron donor, $20 \mu \mathrm{M}$ pentachlorophenol (PCP) as the electron acceptor, and $1 \mathrm{~g}$ humin as redox mediator for dechlorination. Med-A was composed of $\mathrm{NH}_{4} \mathrm{Cl}, 1.00 \mathrm{~g} / \mathrm{L} ; \mathrm{CaCl}_{2} \cdot 2 \mathrm{H}_{2} \mathrm{O}$, $0.05 \mathrm{~g} / \mathrm{L} ; \mathrm{MgCl}_{2} \cdot 6 \mathrm{H}_{2} \mathrm{O}, 0.10 \mathrm{~g} / \mathrm{L} ; \mathrm{K}_{2} \mathrm{HPO}_{4}, 0.4 \mathrm{~g} / \mathrm{L} ; \mathrm{NaHCO}_{3}, 4.00 \mathrm{~g} / \mathrm{L} ;$ and $1 \mathrm{~mL} / \mathrm{L}$ each of SL-10 trace element solution; selenite-tungstate solution; and resazurin was added [35]. The medium $\mathrm{pH}$ was set at $7.0 \pm 0.2$ by sparging with gas mixture of $\mathrm{N}_{2}$ and $\mathrm{CO}_{2}$ in ratio of 4:1. The culture vial (total volume of $120 \mathrm{~mL}$ ) containing $50 \mathrm{~mL}$ of Med A was sealed with butyl rubber stopper and aluminum crimp caps. The headspace of the sealed vial was flushed with gas mixture of $\mathrm{N}_{2}$ and $\mathrm{CO}_{2}$ in ratio of 4:1 for $45 \mathrm{~min}$. Sterilization was done at $121{ }^{\circ} \mathrm{C}$ for $20 \mathrm{~min}$. Addition of vitamin solution [23]; $10 \mathrm{mM}$ Na-acetate; $20 \mu \mathrm{M}$ PCP ( $>90 \%$ purity); and reducing agent titanium nitrilotriacetic acid (Ti-NTA, $0.20 \mathrm{mM}$ ) was carried out prior to the inoculation. Maintenance and development of the consortia were carried out 
by transferring $10 \%(v / v)$ of the bacterial culture for inoculation. The cultures were incubated at $30{ }^{\circ} \mathrm{C}$ in dark for two weeks.

Subsequently, the concentration of Na-acetate in Med-A was decreased to $1 \mathrm{mM}$, and the consortium PCPA1 was obtained. The consortium PCPA1 post third generation showed steady increase in acetate concentration higher than initial concentration of $1 \mathrm{mM}$ after two weeks of incubation along with dechlorination of PCP to lower chlorinated metabolites (Figure S1, Figure S2). As such, the acetogenic consortium PCPA0 was developed from the fifth generation of PCPA1 in the same medium conditions as PCPA1, but the addition of Na-acetate as external electron donor or carbon source was omitted.

\subsection{Timeline Study Using Consortium PCPAO}

Timeline study was carried out using sacrificing cultures of consortium PCPA0 in triplicates (for days 0, 5, 10, and 15) to examine the effects of the following conditions: (a) PCPA0-C1-absence of humin in the condition of PCPA0; (b) PCPA0-C2-absence of reducing agent in the condition of PCPA0; (c) PCPA0-C3-absence of $\mathrm{CO}_{2} / \mathrm{HCO}_{3}{ }^{-}$in condition of PCPA0, that is, bicarbonate buffer was replaced with $20 \mathrm{mM}$ MOPS (3-(N-morpholino)propanesulfonic acid) with nitrogen sparging, and headspace was flushed with $\mathrm{N}_{2}$ only. Control- 1 was provided without bacterial inoculation as the basal condition of PCPA0. The inoculum source was 10th generation of the consortium PCPA0. The conditions are summarized in Table 1.

Table 1. Experimental setup in this study. The notation " + " and "- " indicates the presence and absence of the respective conditions.

\begin{tabular}{|c|c|c|c|c|c|}
\hline Conditions & Humin & Ti-NTA & Buffer & Headspace Composition & Inoculum Source \\
\hline РСРА0 & + & + & $\mathrm{CO}_{2} / \mathrm{HCO}_{3}^{-}$ & $\mathrm{N}_{2} / \mathrm{CO}_{2}$ & PCPA0 \\
\hline PCPA0-C1 & - & + & $\mathrm{CO}_{2} / \mathrm{HCO}_{3}^{-}$ & $\mathrm{N}_{2} / \mathrm{CO}_{2}$ & РСРА0 \\
\hline PCPA0-C2 & + & - & $\mathrm{CO}_{2} / \mathrm{HCO}_{3}^{-}$ & $\mathrm{N}_{2} / \mathrm{CO}_{2}$ & PCPA0 \\
\hline РCPA0-C3 & + & + & MOPS & $\mathrm{N}_{2}$ & PCPA0 \\
\hline Control-1 & + & + & $\mathrm{CO}_{2} / \mathrm{HCO}_{3}{ }^{-}$ & $\mathrm{N}_{2} / \mathrm{CO}_{2}$ & - \\
\hline $\mathrm{A} 0 \mathrm{CO}$ & + & + & $\mathrm{CO}_{2} / \mathrm{HCO}_{3}^{-}$ & $\mathrm{N}_{2} / \mathrm{CO}_{2} / \mathrm{CO}$ & PCPA0 \\
\hline $\mathrm{A} 0 \mathrm{CO}-\mathrm{C} 1$ & + & + & MOPS & $\mathrm{N}_{2} / \mathrm{CO}$ & $\mathrm{A} 0 \mathrm{CO}$ \\
\hline $\mathrm{A} 0 \mathrm{CO}-\mathrm{C} 2$ & - & + & MOPS & $\mathrm{N}_{2} / \mathrm{CO}$ & $\mathrm{A} 0 \mathrm{CO}$ \\
\hline
\end{tabular}

Ti-NTA is the reducing agent used for the anaerobic medium preparation. The term PCPA0 denotes a PCP dechlorinating culture using $0 \mathrm{mM}$ acetate concentration.

\subsection{Effect of Carbon Monoxide (CO)}

Consortium A0CO was developed from the 17th generation of PCPA0 under the same conditions of PCPA0 with exception to $3 \mathrm{~mL}$ addition of carbon monoxide (CO, 0.134 mmoles) into the headspace using gas-tight glass syringe (VICI, Baton Rouge, LA, USA) prior to inoculation. Batch study using consortium A0CO was carried out using the condition of PCPA0-C3 (MOPS buffer instead of bicarbonate buffer) with the addition of $3 \mathrm{~mL}$ of $\mathrm{CO}$ (the condition $\mathrm{A} 0 \mathrm{CO}-\mathrm{C} 1$ ). The A0CO-C2 was provided without addition of humin. The source of inoculum was the fourth generation of consortium A0CO. Acetate and methane productions were compared after two weeks of incubation. The conditions are summarized in Table 1.

\subsection{Bulk Redox Potential of Med-A with Humin}

A H-shaped dual chamber electrochemical cell separated with a proton exchange membrane (Nafion 117, DuPont, Japan, Tokyo) [36] was used for measurement of bulk potential of $4 \mathrm{~g}$ humin in $200 \mathrm{~mL}$ volume of anaerobic Med-A (in absence of vitamin, reducing agent, or PCP) under agitation by mechanical stirring. Coiled platinum (Pt) wires of $0.8 \mathrm{~mm}$ diameter and $1 \mathrm{~m}$ length (Nilaco, Tokyo, Japan) were used as both working, and counter electrodes; and $\mathrm{Ag} / \mathrm{AgCl}$ glass electrode was used as a reference electrode (+250 $\pm 5 \mathrm{mV}$ vs. SHE, Fusheng Analytical Instrument Co., Shanghai, China). The redox potential of the reference electrode was measured post use to check for discrepancies. The $\mathrm{Pt}$ 
wires were brushed clean, sonicated at $40{ }^{\circ} \mathrm{C}$ in pure water, and soaked in $5 \mathrm{~N} \mathrm{HCl}$ solution for $6 \mathrm{~h}$, followed with wash in pure water before use.

\subsection{Chemical Analyses}

The measurement of chlorophenol metabolites using GCMS QP2010 (Shimadzu, Kyoto, Japan); headspace gas analysis using GC-14B gas chromatography equipped with thermal conductivity and flame ionization detectors (Shimadzu, Kyoto, Japan); and organic acid analysis using HPLC (Shimadzu LC-10AT, Kyoto, Japan) was carried out as reported previously [34]. The inorganic carbon analysis was carried out by total organic carbon analyzer (TOC- $\mathrm{V}_{\mathrm{CPH} / \mathrm{CPN}}$, Shimadzu, Kyoto, Japan). Samples for inorganic carbon analysis was filtered using membrane filter (pore size $0.22 \mu \mathrm{m}$ ), diluted in pure anaerobic water in ratio $1: 15$, and stored at $4{ }^{\circ} \mathrm{C}$ prior to analysis. The recovery of chlorophenols ranged from $85-101 \%$. The chemicals used were of Special Grade (JIS) chemicals, purchased from FUJIFILM Wako Pure Chemical Corporation, Osaka, Japan.

\subsection{Microbial Community Structure}

The microbial DNA extraction was carried out from the seventh generation of consortium PCPA0 by FastDNA SPIN kit for soil (MP Biomedicals, Japan, Tokyo, Japan), and was analyzed for taxonomic classification as reported previously [34]. Briefly, Miseq next-generation sequence was carried out for the amplicons targeting V3-V4 region of $16 \mathrm{~S}$ rRNA genes using primer sets-Pro341F (5'-CCT ACG GGN BGC ASC AG-3') and Pro805R (5'-GAC TAC NVG GGT ATC TAA TCC-3').

\section{Results}

\subsection{Humin-Dependent $\mathrm{CO}_{2}$-Reducing Acetogenesis by Consortium PCPA0}

The consortium PCPA0 was developed via acclimatization to acetate-utilizing conditions, initially to $10 \mathrm{mM}$ acetate condition (the consortium PCPA10), then $1 \mathrm{mM}$ acetate condition (the consortium PCPA1), and finally to the condition without acetate, as described above. Any form of external electron donor addition was omitted for the maintenance of the consortium PCPA0. Figure 1 shows the acetate concentration in the consortium PCPA0 after two weeks of incubation, across nine generations. Because $10 \%(v / v)$ transfer of the culture was carried out across the generation using the medium in absence of acetate, steady acetate concentration detected after two weeks of incubation demonstrated acetate production by the consortium PCPA0. The $\mathrm{pH}$ value of the culture did not change after two weeks of incubation. The production of other organic acids such as formate, lactate, or propionate was not detected.

Additionally, anaerobic dechlorination of PCP to less chlorinated metabolites, chiefly metachlorophenol (3-CP) was observed (Table S1), and methane in headspace was detected as well. Hydrogen remained undetected in the headspace measurements. The results suggested acetate production without the use of any electron donor other than humin, which was investigated by timeline study on the consortium PCPA0. Based on the higher stability of acetate production after seventh generation, the microbial community structure of the consortium PCPA0 was judged to become stable, and the consortium PCPA0 post seventh generation or later was used in this study.

Figure 2 shows a timeline of reductive acetogenesis by the consortium PCPA0 using humin. A gradual increase in acetate for the consortium PCPA0 was observed, reaching about $12 \mu$ moles/bottle in the period of 15 days of incubation. In contrast, no acetate production was witnessed in Control-1, the condition without microbial inoculum, confirming that acetate production was due to microbial activity only. Also, no hydrogen or methane production was detected for Control-1. There was little to no increase in acetate for the condition PCPA0-C1 without humin. On the other hand, a steady increase in acetate was observed for the condition PCPA0-C2 without reducing agent, but using humin. The results demonstrated that while reducing agent as Ti-NTA had no pronounced effect in acetate production, humin was critical. In the condition PCPA0-C3 (without $\mathrm{CO}_{2} / \mathrm{HCO}_{3}{ }^{-}$), acetate production was retarded by 10 days. This retardation suggested that $\mathrm{CO}_{2} / \mathrm{HCO}_{3}{ }^{-}$was utilized mainly as inorganic 
carbon source for the acetate production in the consortium PCPA0, and the organic fraction of humin was not the major carbon source for acetate production. The humin dependency in acetate production by the consortium PCPA0 without any other external input of electron donor suggested that humin donated electrons to the microorganisms for $\mathrm{CO}_{2}$ reduction, by functioning as EEM rather than as the organic matter. The electron donation by humin was also observed in the reduction of Med-A with humin, where the bulk redox potential of Med-A measured at $-80.0 \mathrm{mV}$ (vs. $\mathrm{Ag} / \mathrm{AgCl}$ ) with suspended humin $(4 \mathrm{~g} / \mathrm{L})$ at $\mathrm{pH} 6.8$, while it measured at $+42.6 \mathrm{mV}$ (vs. $\mathrm{Ag} / \mathrm{AgCl})$ without humin. Further analysis for the condition PCPA0-C3 suggested that the retarded acetate production would be attributed to the $\mathrm{CO}_{2}$ carryover by $10 \%(v / v)$ culture transfer for the inoculation (Figure S3).

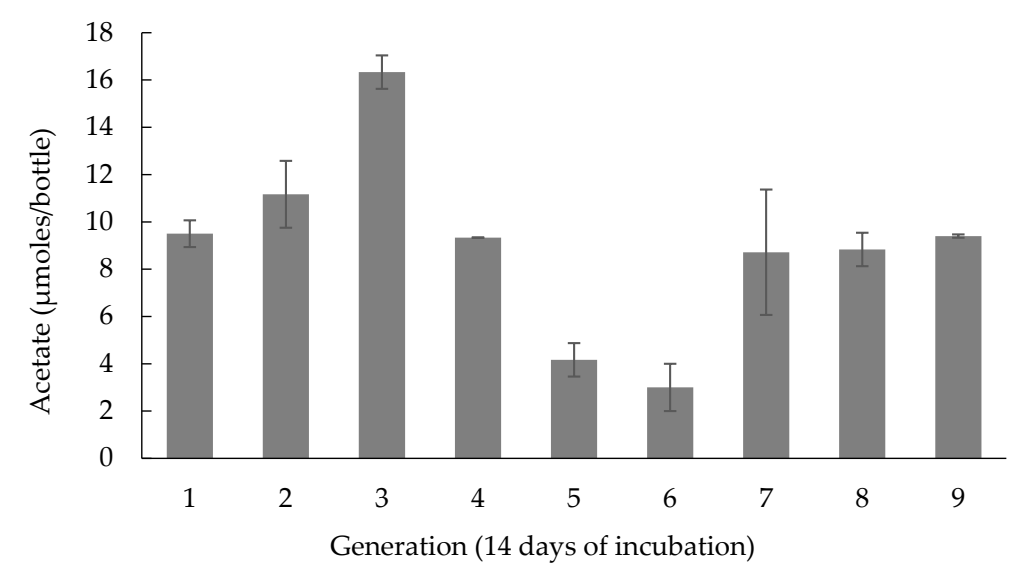

Figure 1. Acetate concentration observed across the generations in the consortium PCPA0. The vertical bars exhibit mean acetate amount ( \pm standard deviation) for the triplicates after two weeks of the incubation. No external electron donor was added in the form of organic acids, or inorganic donor, or organic solvents. Nearly the same acetate concentration after two weeks of incubation across the seven generations indicated stability in the activity of the consortium PCPA0. The x-axis $(n=0,1, \ldots, 9)$ represents the successive generations of the consortium PCPA0.

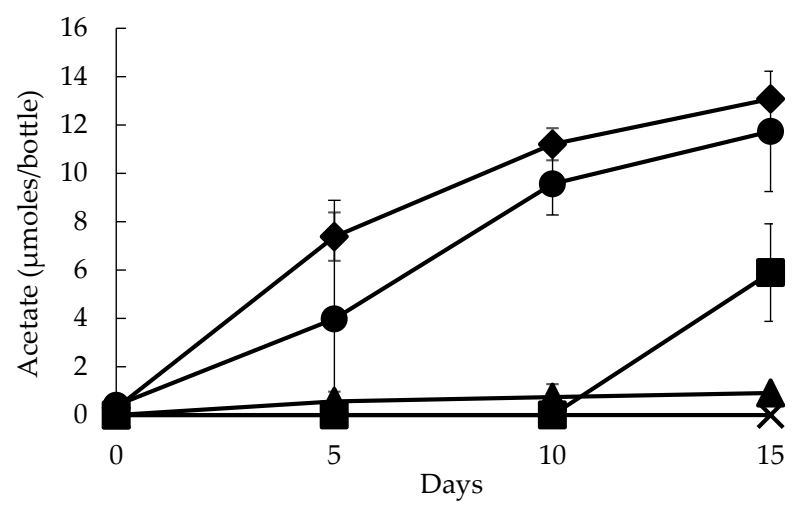

Figure 2. Autotrophic reductive acetogenesis by humin-dependent consortium PCPA0. The data are plotted for the self-sacrificing triplicates used for the batch culture for the timeline period of $0,5,10$, and 15 days, except for PCPA0 where duplicates were studied. PCPA0 represents the 11th generation of consortium PCPA0 in Med-A, that is, conditioned to $\mathrm{CO}_{2} / \mathrm{HCO}_{3}{ }^{-}$in medium, and headspace is flushed with $\mathrm{N}_{2} / \mathrm{CO}_{2}$; and humin $1 \mathrm{~g}$ as well as $0.20 \mathrm{mM}$ of reducing agent (Ti-NTA) was added to the medium (•). PCPA0-C1 had microbial source without humin in Med-A under $\mathrm{HCO}_{3}{ }^{-} / \mathrm{CO}_{2}$ condition (ム) with $\mathrm{N}_{2} / \mathrm{CO}_{2}$ in headspace. PCPA0-C2 used both humin and microbial source in Med-A, that is, under $\mathrm{HCO}_{3}{ }^{-} / \mathrm{CO}_{2}$ condition, but reducing agent was not added $(\diamond)$. PCPA0-C3 used both bacteria and humin, but $\mathrm{CO}_{2} / \mathrm{HCO}_{3}{ }^{-}$was substituted with MOPS in Med-A, and headspace was flushed with $\mathrm{N}_{2}$ only (घ); Control-1 used only humin in Med-A (x) under $\mathrm{N}_{2} / \mathrm{CO}_{2}$ atmosphere without bacteria. The acetate values represent the mean with standard deviation shown by vertical lines. 


\subsection{WLP in the Acetogenesis by Consortium PCPAO}

Reductive acetogenesis using $\mathrm{CO}_{2}$ as the terminal electron acceptor suggested the presence of WLP in the consortium PCPA0. The PCR targeting the gene encoding formyltetrahydrofolate synthetase (FTHFS) [37], a key enzyme in WLP, gave the amplified products around 1.1 kilo base pairs (Figure S4), supporting the occurrence of WLP in the consortium.

Humin dependency for the electron donation was also witnessed in the conversion of $\mathrm{CO}$ to acetate in the consortium A0CO. CO is the substrate of carbon monoxide dehydrogenase/acetyl-CoA synthase, an essential enzymatic complex for WLP, although CO also functions as the reducing agent. The condition A0CO-C1 with humin showed acetate production; whereas no acetate was detected at all for A0CO-C2 without humin (Figure 3). The results are consistent with the involvement of WLP in the acetogenesis by consortium PCPA0. On the other hand, methane production was observed in the conditions of both A0CO-C1 and A0CO-C2. Methane production remained unaffected by the presence of humin. The methanogenesis observed would be supported by the reducing power of $\mathrm{CO}$ as the inorganic electron donor $\left(E^{o^{\prime}}, \mathrm{CO} / \mathrm{CO}_{2}=-520 \mathrm{mV}\right)[38]$.

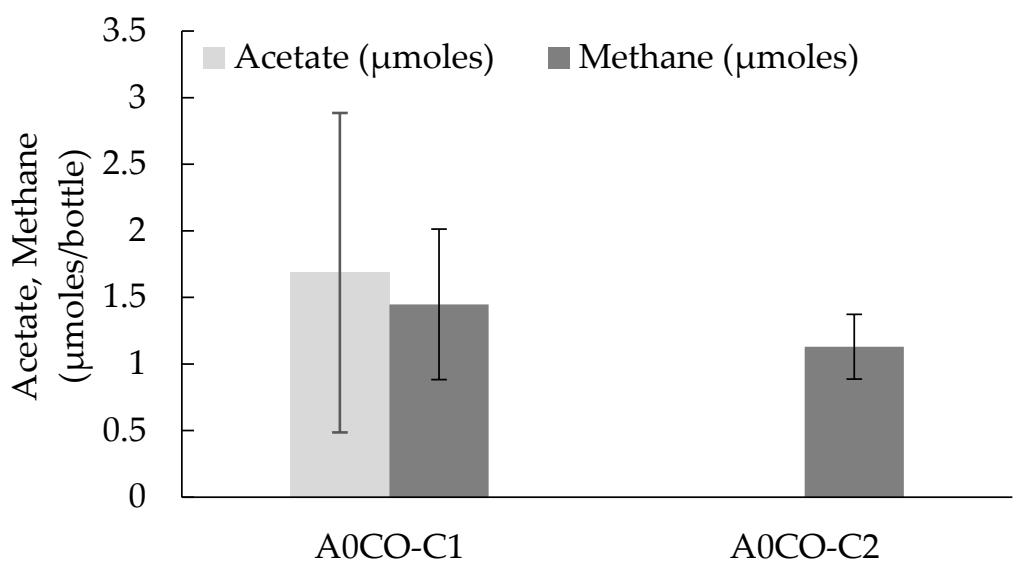

Figure 3. Acetate production and methane generation for conditions A0CO-C1 and A0CO-C2. The condition A0CO-C1 was studied using $1 \mathrm{~g}$ humin/bottle, whereas no humin was added to the condition A0CO-C2. The vertical bars are representative data of the triplicates studied for two weeks incubation, with the vertical lines as the standard deviation.

\subsection{Microbial Community Structure of Consortium PCPAO}

Figure 4 represents the microbial community structure of consortium PCPA0 at the order level. The bacteria classified into the order Clostridiales (Firmicutes) occupied $71.8 \pm 2.5 \%$ of total population. Other major groups belonged to Bacteroidales (Bacteroidetes, $11.8 \pm 2.2 \%$ ), Rhodocyclales ( $\beta$-Proteobacteria, $9.2 \pm 1.5 \%$ ), Desulfovibrionales ( $\delta$-Proteobacteria, $1.3 \pm 0.2 \%$ ), and Spirochaetales (Spirochaetes, $1.5 \pm 0.8 \%$ ). The microbial community structure was in accordance with the $\mathrm{CO}_{2}$-reducing acetogenesis because WLP has been observed mostly in Firmicutes, and some in $\delta$-Proteobacteria and Spirochaetes [8,38]. Lachnospiraceae $(21.6 \pm 1.3 \%)$ and Ruminococcaceae $(16.4 \pm 0.7 \%)$, two major family in Clostridiales detected, have been reported as $\mathrm{CO}_{2}$-reducing acetogens [39]. Dehalobacter occupying $3.7 \pm 0.8 \%$ of total abundance was considered as the PCP-dechlorinating bacterium, utilizing reduced humin as the electron donor [19]. The $\mathrm{CH}_{4}$ production was attributed to Methanobacteriaceae (Euryarchaeota, $<0.35 \%$ abundance), $\mathrm{CO}_{2}$-reducing methanogen with WLP [40]. 


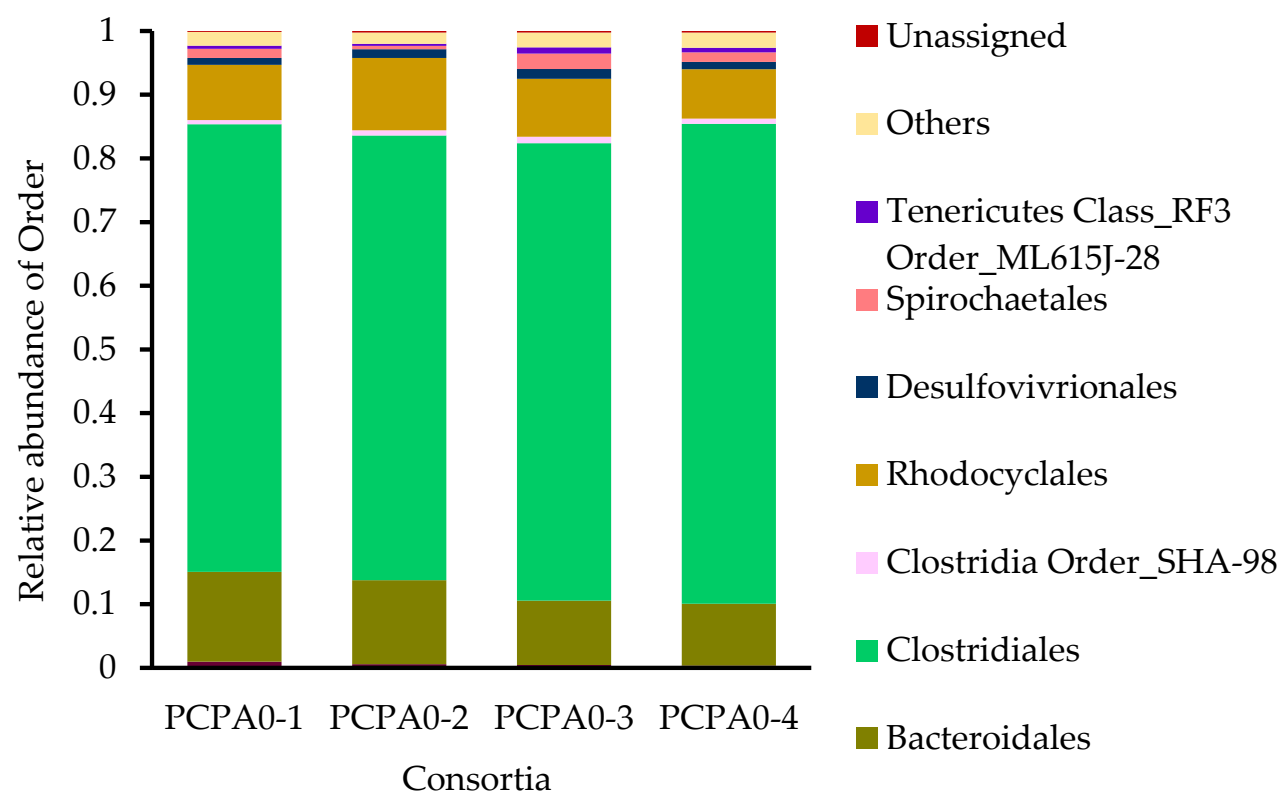

Figure 4. Community structure of consortium PCPA0 based on 16S rRNA gene sequencing. The data shows the community structures of four replicates of the consortium PCPA0, individually. "Others" denotes the populations less than $0.5 \%$ abundance. "Unassigned" represents the genes that were not assigned to any taxonomic position by blast sequencing.

\subsection{Electron Donating Capacity of Humin}

It is understood that acetogenesis through WLP is not constrained by use of the organic substrates, hydrogen, or any other electron donors, but only requires production of acetate through $\mathrm{CO}_{2}$ reduction $[8,38]$. In this study, the acetogenic consortium PCPA0 was considered to utilize electrons from humin as the electron mediator. Methanogenesis and anaerobic PCP dechlorination observed in the consortium PCPA0 would utilize the electrons from humin. Table 2 shows the estimation of electron-donating capacity of humin based on the amount of acetate produced, as well as from the amount of methane due to methanogenesis, and chlorophenol metabolites in anaerobic PCP dechlorination based on the following equations [41-43].

$$
\begin{gathered}
2 \mathrm{CO}_{2}+4 \mathrm{H}_{2} \leftrightarrow \mathrm{CH}_{3} \mathrm{COOH}+2 \mathrm{H}_{2} \mathrm{O} \\
\mathrm{CO}_{2}+4 \mathrm{H}_{2} \rightarrow \mathrm{CH}_{4}+2 \mathrm{H}_{2} \mathrm{O} \\
\mathrm{C}_{6} \mathrm{Cl}_{5-\mathrm{x}} \mathrm{H}_{\mathrm{x}} \mathrm{OH}+\mathrm{H}_{2} \rightarrow \mathrm{C}_{6} \mathrm{Cl}_{4-\mathrm{x}} \mathrm{H}_{\mathrm{x}+1} \mathrm{OH}+\mathrm{HCl},(\mathrm{x}=0-5)
\end{gathered}
$$

In the equations above, hydrogen is shown as the reducing equivalent, where one hydrogen atom equals to one electron plus one proton. The production of one molecule of acetic acid from $\mathrm{CO}_{2}$ requires eight reducing equivalents. Again, the production of methane requires eight reducing equivalents, and the anaerobic dechlorination of one chlorine atom requires two reducing equivalents. In Table 2, the difference in the amounts of acetate, methane, and chlorophenols between PCPA0 and PCPA0-C1 indicated the tendency of electron donation of humin to the respective group of microorganisms. Mass balance study of the chlorophenols indicated possible decomposition of phenol structure in consortium PCPA0, as the unaccounted chlorophenols. The unaccounted chlorophenols were estimated to range from zero to thirty percent. In consideration with benzoyl-CoA pathway [44] for phenol decomposition, the acetate production from chlorophenols was estimated. The results showed that the possible contribution of chlorophenols was not more than $3 \mu \mathrm{mols} /$ bottle $(27 \%)$ for acetate production. The total electron-donating capacity of humin was estimated to be larger than $87 \mu$ eeq/g humin for the consortium PCPA0, where electron donation towards acetate production specifically was larger than 
$62 \mu \mathrm{eeq} / \mathrm{g}$ humin in consideration with the other biochemical pathways. This suggested that methane decomposition or phenol decomposition did not contribute as secondary influences for the acetate production observed in the consortium PCPA0.

Table 2. Metabolites produced by the consortium PCPA0 and the estimated electron-donating capacity of humin $(1 \mathrm{~g} / \mathrm{bottle})$.

\begin{tabular}{|c|c|c|c|c|}
\hline \multirow{2}{*}{ Observed Reactions } & \multicolumn{2}{|c|}{ Experimental Conditions } & \multirow{2}{*}{$\begin{array}{l}\text { Difference Made by } \\
\text { Humin Addition } \\
\text { Mmoles/g-Humin } \\
\text { (Mean } \pm \text { SD) }\end{array}$} & \multirow{2}{*}{ 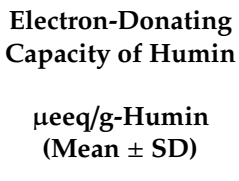 } \\
\hline & $\begin{array}{c}\text { PCPA0 } \\
\mu \text { moles/Bottle } \\
(\text { Mean } \pm \text { SD) }\end{array}$ & $\begin{array}{c}\text { PCPA0-C1 } \\
\mu \text { moles/Bottle } \\
(\text { Mean } \pm \text { SD) }\end{array}$ & & \\
\hline Acetate Production & $11.75 \pm 1.75$ & $0.91 \pm 0.04$ & $10.80 \pm 1.75$ & $86.4 \pm 14.0$ \\
\hline Methane Production & $2.25 \pm 0.92$ & n.d. ${ }^{1}$ & $2.25 \pm 0.92$ & $18.0 \pm 7.36$ \\
\hline $\begin{array}{c}\text { Total capacity of electron } \\
\text { donation from humin }\end{array}$ & - & - & - & 87.2 \\
\hline
\end{tabular}

The table compares the electron-donating capacity of the consortium PCPA0 with that of the condition PCPA0-C1 without humin studied in the same timeline. The data is representative of the triplicates mean and standard deviation (SD) post fifteen days of incubation. The electron-donating capacity as electron equivalent (eeq) of $1 \mathrm{~g}$ humin per bottle has been calculated based on the reducing equivalents per equation 1-3. 1 "n.d." denotes "not detected". 2 "Unaccounted chlorophenols" denotes the unaccounted chlorophenols based on the mass balance of chlorophenols in the bottle. ${ }^{3}$ The equivalent contribution as acetate production from phenol has been calculated based on benzyl-CoA pathway [44], and the equivalent contribution as electrons was subtracted from the estimated electron-donating capacity of humin.

\section{Discussion}

It was demonstrated for the first time that humin supported microbial $\mathrm{CO}_{2}$-reducing acetogenesis by donating electrons as EEM to the consortium PCPA0. The comparison of acetate production in the consortium PCPA0 under the different conditions clearly showed that acetate was not produced from organic fraction of humin but from $\mathrm{CO}_{2}$ (Figure 2). The consortium PCPA0, predominated by Clostridiales (Figure 4), was maintained with humin as EEM for sole source of electrons with the presence of $\mathrm{CO}_{2} / \mathrm{HCO}_{3}{ }^{-}$as carbon source over the generations (Figure 1), suggesting the occurrence of microbial growth under the energy-limited conditions. Humin also supported dechlorination and methanogenesis of the consortium PCPA0 (Table S1). These suggested that under energy-limited conditions, humin served electrons as a solid-phase EEM for the multiple reactions by microorganisms including electroautotrophs.

Supporting microbial $\mathrm{CO}_{2}$-reducing acetogenesis by humin as EEM suggested that humin can donate electrons for highly reduced reactions, because microbial $\mathrm{CO}_{2}$-reducing acetogenesis involves complex enzymes which require more reducing conditions than $-290 \mathrm{mV}\left(E^{o^{\prime}}\right)$ [43]. Previous study [25] showed the electron transfer from humin to the microorganisms implementing reductive dechlorination $\left(E^{o^{\prime}}\right.$, higher than $\left.+300 \mathrm{mV}\right)[41]$; denitrification $\left(E^{o^{\prime}}\right.$, higher than $\left.+400 \mathrm{mV}\right)$, iron reduction $\left(E^{o^{\prime}}\right.$, about $\left.0 \mathrm{mV}\right)$, and dissimilatory nitrate reduction to ammonia $\left(E^{0^{\prime}}\right.$, about $\left.+360 \mathrm{mV}\right)$ [45]. It was also previously suggested the redox potential of humin ranging from $+272 \mathrm{mV}$ to $-300 \mathrm{mV}$ (vs. SHE) as redox mediator $[19,22,25]$, indicating that the electron transfer from humin was favorable. However, for the $\mathrm{CO}_{2}$-reducing acetogenesis, the electron donation from humin would not be expected based on the redox potential of humin. In a recent study it was argued that a higher redox potential of $-340 \mathrm{mV}$ (vs. SHE) could induce such reductive acetogenesis in Acetobacterium woodii [46]. It is understood that the organic chemical structures of HSs change three dimensionally depending on the environmental conditions [47]. Therefore, it can only be proposed that the various domains with different redox potentials are present in organic fractions of humin, and the highly reduced domains storing electrons were accessible to the humin-dependent acetogenic community present in the consortium PCPA0 for electron harvest, as shown in Figure 5. 


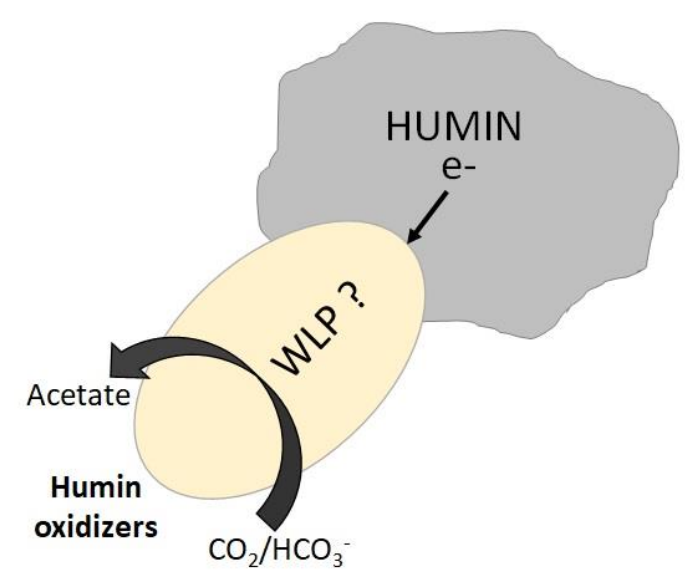

Figure 5. Microbial $\mathrm{CO}_{2}$-reducing acetogenesis supported by humin as EEM for the electron donation to the consortium PCPA0 in the $\mathrm{CO}_{2} / \mathrm{HCO}_{3}{ }^{-}$-buffered medium.

In comparison to the redox potential of half reaction of $\mathrm{CO}_{2} / \mathrm{CH}_{3} \mathrm{COOH}$ at $-290 \mathrm{mV}\left(E^{0^{\prime}}\right)$, the redox potential of $\mathrm{CO}_{2} / \mathrm{CH}_{4}$ at $-230 \mathrm{mV}\left(E^{o^{\prime}}\right)$ [42], and those in the series of PCP dechlorination to phenol which range from $+333 \mathrm{mV}$ to $+424 \mathrm{mV}\left(E^{o^{\prime}}\right)$ [41] are higher. As the preference of electron-accepting reactions at higher redox potentials comes first, before those at lower redox potentials, the reducing reactions should occur in the order of anaerobic PCP dechlorination, methanogenesis, and lastly, acetogenesis. This explained the result that most of the PCP was dechlorinated in the consortium PCPA0, but not the result that acetogenesis was dominant over methanogenesis. This could be attributed only to the predominance of acetogenic microorganisms in the consortium.

The consortium PCPA0 with humin in the $\mathrm{CO}_{2} / \mathrm{HCO}_{3}{ }^{-}$-buffered dechlorinating medium did not produce longer-chain organic acids, and even lactate, while acetate production was witnessed. This indicated energy-limited conditions, as production of longer-chain fatty acids requires more energy [33]. The detection of formate was expected [5], but not in the consortium PCPA0 with humin where WLP was considered to be involved in the autotrophic acetogenesis, as indicated by the acetogenesis from CO (Figure 3) and the presence of FTHFS genes (Figure S4). The electron transfer between humin and WLP for acetate-producing microorganisms hints at complex biochemical interaction (Figure 5), and further study is required to explore the mechanism of EEM function of humin. Although Lachnospiraceae and Ruminococcaceae were detected as major Clostridiales in the consortium PCPA0 (Figure 4), the possible involvement of other bacteria cannot be discarded. Thus, the identification of microorganisms responsible for the humin-dependent acetogenesis would be critical for elucidation of the mechanism.

\section{Conclusions}

This study demonstrated that humin can serve extracellular electrons to microbial $\mathrm{CO}_{2}$-reducing acetogenesis, requiring highly reduced redox potential at $-290 \mathrm{mV}\left(E^{o^{\prime}}\right)$, under energy-limited dark conditions. This distinctive feature of humin was successfully used by the anaerobic consortium PCPA0 for autotrophic acetate production ( $11 \mu$ moles/g-humin) in absence of any degradable organic compounds, hydrogen, or electricity. The major group of bacteria in the consortium PCPA0 belonged to the order Clostridiales, followed by Bacteroidales, Rhodocyclales, and Desulfovibrionales. Reductive dechlorination and methanogenesis observed in the consortium PCPA0 were also supported by humin as electron donor. The energetics in the anaerobic consortium PCPA0 suggested that highly reduced domain occluded in humin could be accessed by certain group of microorganisms for electron harvest. Further study should be carried out to elucidate the mechanism of EEM function of humin, especially the electron-donating mechanism for microbial $\mathrm{CO}_{2}$-reducing acetogenesis under the conditions exerted by the consortium PCPA0. Considering the ubiquitous presence of humin in the environment, 
the findings significantly contribute in understanding the microbial reactions involved in the carbon cycle on the earth, and open scope to study the flexibility of using humin as the sole source of energy for bioremediation.

Supplementary Materials: The following are available online at http://www.mdpi.com/1660-4601/17/12/4211/s1, Table S1: Dechlorination metabolites detected in the timeline study using consortium PCPA0; Figure S1: Trend of acetate in consortium PCPA1 after two weeks incubation; Figure S2: Trend of dechlorination metabolites in consortium PCPA1 after two weeks incubation; Figure S3: Inorganic carbon as carbon dioxide in the mineral medium and headspace under the condition of PCPA0-C3; Figure S4: PCR products of consortium PCPA0 using specific primer set targeting the gene encoding formyltetrahydrofolate synthetase (FTHFS).

Author Contributions: Conceptualization, A.K.: Data Curation, M.L. and T.A.; Funding acquisition, T.A., T.K. and A.K.; Methodology, M.L., T.A., T.K., and A.K.; Investigation, M.L. and T.A.; Project Administration, A.K.; Writing-Original Draft Presentation, M.L.; Writing-Review and Editing, A.K.; Visualization, M.L.; Supervision, A.K. All authors read and approved the final manuscript.

Funding: This study was supported in part by a Grant-in-Aid for Scientific Research (17H01899, 20H04363) from the Japan Society of Promotion of Science (JSPS), by cooperative study program of IMaSS, Nagoya University (2019 project), by 21st Century Foundation (2019 project), and by Institute of Fermentation, Osaka (L-2019-003).

Acknowledgments: The authors thank Toyoko Demachi and Shozo Ohta for their support in laboratory assistance.

Conflicts of Interest: The authors declare no conflicts of interest. The funders had no role in the design of the study; in the collection, analyses, or interpretation of data, in the writing of the manuscript, or in the decision to publish the results.

\section{References}

1. Drake, H.L.; Gößner, A.S.; Daniel, S.L. Old Acetogens, New Light. Ann. N. Y. Acad. Sci. 2008, 1125, 100-128. [CrossRef]

2. Fuchs, G. Alternative Pathways of Carbon Dioxide Fixation: Insights into the Early Evolution of Life? Annu. Rev. Microbiol. 2011, 65, 631-658. [CrossRef]

3. Lever, M.A. Acetogenesis in the Energy-Starved Deep Biosphere-A Paradox? Front. Microbiol. 2012, 2, 284. [CrossRef] [PubMed]

4. Oren, A. There Must be an Acetogen Somewhere. Front. Microbiol. 2012, 3, 22. [CrossRef] [PubMed]

5. Schuchmann, K.; Müller, V. Energetics and Application of Heterotrophy in Acetogenic Bacteria. Appl. Environ. Microbiol. 2016, 82, 4056-4069. [CrossRef]

6. Aryal, N.; Tremblay, P.L.; Lizak, D.M.; Zhang, T. Performance of different Sporomusa species for the microbial electrosynthesis of acetate from carbon dioxide. Bioresour. Technol. 2017, 233, 184-190. [CrossRef] [PubMed]

7. Cotton, C.A.; Edlich-Muth, C.; Bar-Even, A. Reinforcing carbon fixation: $\mathrm{CO}_{2}$ reduction replacing and supporting carboxylation. Curr. Opin. Biotechnol. 2018, 49, 49-56. [CrossRef] [PubMed]

8. Ragsdale, S.W.; Pierce, E. Acetogenesis and the Wood-Ljungdahl pathway of $\mathrm{CO}_{2}$ fixation. Biochim. Biophys. Acta (BBA) Proteins Proteom. 2008, 1784, 1873-1898. [CrossRef] [PubMed]

9. He, J.; Sung, Y.; Dollhopf, M.E.; Fathepure, B.Z.; Tiedje, J.M.; Löffler, F.E. Acetate versus Hydrogen as Direct Electron Donors To Stimulate the Microbial Reductive Dechlorination Process at Chloroethene-Contaminated Sites. Environ. Sci. Technol. 2002, 36, 3945-3952. [CrossRef]

10. Jeremiasse, A.W.; Hamelers, H.V.M.; Croese, E.; Buisman, C.J.N. Acetate enhances startup of a $\mathrm{H}_{2}$-producing microbial biocathode. Biotechnol. Bioeng. 2012, 109, 657-664. [CrossRef]

11. Duhamel, M.; Edwards, E.A. Growth and yields of dechlorinators, acetogens, and methanogens during reductive dechlorination of chlorinated ethenes and dihaloelimination of 1,2-dichloroethane. Environ. Sci. Technol. 2007, 41, 2303-2310. [CrossRef]

12. Rumpel, C.; Kögel-Knabner, I. Deep soil organic matter-a key but poorly understood component of terrestrial C cycle. Plant Soil 2011, 338, 143-158. [CrossRef]

13. Torn, M.S.; Trumbore, S.E.; Chadwick, O.A.; Vitousek, P.M.; Hendricks, D.M. Mineral control of soil organic carbon storage and turnover. Nature 1997, 389, 170-173. [CrossRef]

14. Van Elsas, J.D. Modern Soil Microbiology; Taylor \& Francis: Abington, UK, 1997; p. 708. ISBN1 0849390346. ISBN2 9780849390340.

15. Hayes, M.H.B.; Mylotte, R.; Swift, R.S. Humin: Its Composition and Importance in Soil Organic Matter. Adv. Agron. 2017, 143, 47-138. 
16. Gobat, J.M.; Aragno, M.; Matthey, W. The Living Soil: Fundamentals of Soil Science and Soil Biology; Science Publishers Inc.: Enfield, NH, USA; Plymouth, UK, 2004; p. 602. ISBN 1578082102.

17. Lovley, D.R.; Fraga, J.L.; Coates, J.D.; Blunt-Harris, E.L. Humics as an electron donor for anaerobic respiration. Environ. Microbiol. 1999, 1, 89-98. [CrossRef] [PubMed]

18. Lovley, D.R.; Coates, J.D.; Blunt-Harris, E.L.; Phillips, E.J.P.; Woodward, J.C. Humic substances as electron acceptors for microbial respiration. Nature 1996, 382, 445-448. [CrossRef]

19. Zhang, C.; Katayama, A. Humin as an electron mediator for microbial reductive dehalogenation. Environ. Sci. Technol. 2012, 46, 6575-6583. [CrossRef] [PubMed]

20. Roden, E.E.; Kappler, A.; Bauer, I.; Jiang, J.; Paul, A.; Stoesser, R.; Konishi, H.; Xu, H. Extracellular electron transfer through microbial reduction of solid-phase humic substances. Nat. Geosci. 2010, 3, 417-421. [CrossRef]

21. Stern, N.; Mejia, J.; He, S.; Yang, Y.; Ginder-Vogel, M.; Roden, E.E. Dual Role of Humic Substances As Electron Donor and Shuttle for Dissimilatory Iron Reduction. Environ. Sci. Technol. 2018, 52, 5691-5699. [CrossRef] [PubMed]

22. Zhang, C.; Zhang, D.; Xiao, Z.; Li, Z.; Suzuki, D.; Katayama, A. Characterization of humins from different natural sources and the effect on microbial reductive dechlorination of pentachlorophenol. Chemosphere 2015, 131, 110-116. [CrossRef] [PubMed]

23. Zhang, C.; Li, Z.; Suzuki, D.; Ye, L.; Yoshida, N.; Katayama, A. A humin-dependent Dehalobacter species is involved in reductive debromination of tetrabromobisphenol A. Chemosphere 2013, 92, 1343-1348. [CrossRef] [PubMed]

24. Xiao, Z.; Awata, T.; Zhang, D.; Zhang, C.; Li, Z.; Katayama, A. Enhanced denitrification of Pseudomonas stutzeri by a bioelectrochemical system assisted with solid-phase humin. J. Biosci. Bioeng. 2016, 122, 85-91. [CrossRef] [PubMed]

25. Zhang, D.; Zhang, C.; Xiao, Z.; Suzuki, D.; Katayama, A. Humin as an electron donor for enhancement of multiple microbial reduction reactions with different redox potentials in a consortium. J. Biosci. Bioeng. 2015, 119, 188-194. [CrossRef]

26. Reda, T.; Plugge, C.M.; Abram, N.J.; Hirst, J. Reversible interconversion of carbon dioxide and formate by an electroactive enzyme. Proc. Natl. Acad. Sci. USA 2008, 105, 10654-10658. [CrossRef]

27. Baumberger, J.P.; Juürgensen, J.J.; Bardwell, K. The coupled redox potential of the lactate-enzyme -pyruvate system. J. Gen. Physiol. 1933, 16, 961-976. [CrossRef] [PubMed]

28. Santos, D.M.F.; Sequeira, C.A.C. Sodium borohydride determination by measurement of open circuit potentials. J. Electroanal. Chem. 2009, 627, 1-8. [CrossRef]

29. Chen, L.; Tremblay, P.-L.; Mohanty, S.; Xu, K.; Zhang, T. Electrosynthesis of acetate from $\mathrm{CO}_{2}$ by a highly structured biofilm assembled with reduced graphene oxide-tetraethylene pentamine. J. Mater. Chem. A 2016, 4, 8395-8401. [CrossRef]

30. Jourdin, L.; Freguia, S.; Donose, B.C.; Chen, J.; Wallace, G.G.; Keller, J.; Flexer, V. A novel carbon nanotube modified scaffold as an efficient biocathode material for improved microbial electrosynthesis. J. Mater. Chem. A 2014, 2, 13093-13102. [CrossRef]

31. Glasser, N.R.; Saunders, S.H.; Newman, D.K. The Colorful World of Extracellular Electron Shuttles. Annu. Rev. Microbiol. 2017, 71, 731-751. [CrossRef]

32. Agostino, V.; Rosenbaum, M.A. Sulfate-reducing electroautotrophs and their applications in bioelectrochemical systems. Front. Energy Res. 2018, 6, 56. [CrossRef]

33. Müller, V.; Hess, V. The Minimum Biological Energy Quantum. Front. Microbiol. 2017, 8, 2019. [CrossRef] [PubMed]

34. Laskar, M.; Awata, T.; Kasai, T.; Katayama, A. Anaerobic Dechlorination by a Humin-Dependent Pentachlorophenol-Dechlorinating Consortium under Autotrophic Conditions Induced by Homoacetogenesis. Int. J. Environ. Res. Public Health 2019, 16, 2873. [CrossRef]

35. Zhang, D.; Zhang, C.; Li, Z.; Suzuki, D.; Komatsu, D.D.; Tsunogai, U.; Katayama, A. Electrochemical stimulation of microbial reductive dechlorination of pentachlorophenol using solid-state redox mediator (humin) immobilization. Bioresour. Technol. 2014, 164, 232-240. [CrossRef] [PubMed]

36. Tang, Y.; Karlsson, A.M.; Santare, M.H.; Gilbert, M.; Cleghorn, S.; Johnson, W.B. An experimental investigation of humidity and temperature effects on the mechanical properties of perfluorosulfonic acid membrane. Mater. Sci. Eng. A 2006, 425, 297-304. [CrossRef] 
37. Henderson, G.; Leahy, S.C.; Janssen, P.H. Presence of novel, potentially homoacetogenic bacteria in the rumen as determined by analysis of formyltetrahydrofolate synthetase sequences from ruminants. Appl. Environ. Microbiol. 2010, 76, 2058-2066. [CrossRef] [PubMed]

38. Schuchmann, K.; Müller, V. Autotrophy at the thermodynamic limit of life: A model for energy conservation in acetogenic bacteria. Nat. Rev. Microbiol. 2014, 12, 809-821. [CrossRef]

39. Gagen, E.J.; Wang, J.; Padmanabha, J.; Liu, J.; De Carvalho, I.P.C.; Liu, J.; Webb, R.I.; Al Jassim, R.; Morrison, M.; Denman, S.E.; et al. Investigation of a new acetogen isolated from an enrichment of the tammar wallaby forestomach. BMC Microbiol. 2014, 14, 1-14. [CrossRef]

40. Horn, M.A.; Matthies, C.; Küsel, K.; Schramm, A.; Drake, H.L. Hydrogenotrophic methanogenesis by moderately acid-tolerant methanogens of a methane-emitting acidic peat. Appl. Environ. Microbiol. 2003, 69, 74-83. [CrossRef]

41. Dolfing, J.; Novak, I. The Gibbs free energy of formation of halogenated benzenes, benzoates and phenols and their potential role as electron acceptors in anaerobic environments. Biodegradation 2014, 26, 15-27. [CrossRef]

42. Ferry, J.G. CO Dehydrogenase of Methanogens. In Acetogenesis; Drake, H.L., Ed.; Springer: Boston, MA, USA, 1994; pp. 539-556. ISBN 978-1-4613-5716-2.

43. Ragsdale, S.W. Enzymology of the Woods-Ljundahl Pathway of Acetogenesis. Ann. N. Y. Acad. Sci. 2008, 1125, 129-136. [CrossRef] [PubMed]

44. Harwood, C.S.; Burchhardt, G.; Herrmann, H.; Fuchs, G. Anaerobic metabolism of aromatic compounds via the benzoyl-CoA pathway. FEMS Microbiol. Rev. 1998, 22, 439-458. [CrossRef]

45. Weber, K.A.; Achenbach, L.A.; Coates, J.D. Microorganisms pumping iron: Anaerobic microbial iron oxidation and reduction. Nat. Rev. Microbiol. 2006, 4, 752-764. [CrossRef] [PubMed]

46. Bar-Even, A. Does acetogenesis really require especially low reduction potential? Biochim. Biophys. Acta Bioenerg. 2013, 1827, 395-400. [CrossRef] [PubMed]

47. Kleber, M.; Johnson, M.G. Advances in understanding the molecular structure of soil organic matter. Adv. Agron. 2010, 106, 77-142.

(C) 2020 by the authors. Licensee MDPI, Basel, Switzerland. This article is an open access article distributed under the terms and conditions of the Creative Commons Attribution (CC BY) license (http://creativecommons.org/licenses/by/4.0/). 